\title{
La trayectoria social del arte y cultura nogalense: artistas, colectivos, circunstancias, reflexiones y oportunidades
}

\author{
Gustavo Cantero Meza \\ Universidad AutónomaMetropolitana Iztapalapa, Ciudad de México,México. \\ Email: carguscan@hotmail.com
}

Resumen: La frontera norte de México se interpreta como lugar de estereotipos asociados al desarrollo industrial, desenfreno y violencia, preservando así connotaciones negativas y leyendas negras. Este trabajo ofrece miradas alternas sobre la frontera que subrayan su sentido, valor social y humano desde el arte y los colectivos culturales de la ciudad de Nogales. Es cierto que por la frontera norte de México han ocurrido sucesos indignantes que llaman a la reflexión y la protesta. También es cierto que la frontera no es ese lugar interpretado como aislado y culturalmente distante de la realidad mexicana y mundial. El arte y las expresiones culturales fronterizas son inequívocas: capturan el sentido de problemáticas sociales resignificándolas; colaboran con la reflexión social local y regional; aportan colorido e identidad; movilizan nuevos públicos; relacionan a participantes/creadores que se organizan como sociedad civil, para cooperar con el gobierno y organismos civiles al otro lado de la frontera.

Palabras clave: espacio público, colectivos, organismo de la sociedad civil, arte fronterizo, identidad fronteriza.

\section{The social path of culture and arts in Nogales: groups, artists, circumstances opportunities and reflections}

\begin{abstract}
Mexico's northern border has been interpreted as a place of stereotypes related with industrial development, violence and wildness, thus preserving negative meanings and black legends. This paper provides alternative views about the border that highlights its social sense, and social and human values as seen from artistic and cultural collectives in Nogales city. It is true that in Mexico's northern border outrageous events that call for reflection and protest have occurred. But is also true, that border is not that place interpreted as isolated and culturally distant from global and Mexican reality. Border cultural and artistic expressions are unmistakable: they capture the sense of social problems and remeanings them, collaborate with social analysis in regional and local scale, provide colorful identity in public spaces, mobilize new audiences and relates to participants/ creators who organize themselves as civil society in order to cooperate with local government and NGOs across the border.
\end{abstract}

Key words: public space, collectives, NGOs, border arts, border identity. 


\section{Atrajetória social da arte e cultura nogalense: artistas, coletivos, circunstancias, reflexões eoportunidades}

Resumo: Afronteira norte de México se interpreta como lugar de estereótipos associados a o desenvolvimento industrial, descomedimento e violência, preservando assimas conotações negativas e lendas negras. Este trabalho ofereceolhares alternativos sobre a fronteira que sublinham seu sentido, valor social e humano desde aarte e o scoletivos culturais da cidade de Nogales. Certamente na fronteira norte de México tem acontecido eventos indignantes que chamam à reflexão e à revolta. Também é certo que a fronteira não é esse lugar interpretado como isoladoe culturalmente afastado da realidade mexicana e mundial. A arte e as expressões culturais fronteiriças são inequívocas: capturamosentido de problemáticas sociais resinificando elas; colaboramcom a reflexão social local e regional; aportam colorido e identidade; mobilizam novos públicos; relacionam a participantes/criadores que se organizam como sociedade civil, para cooperar com o governo e organismos civis localizados doutro lado da fronteira.

Palavras chave: espaço público, coletivos, organismo dasociedade civil, arte fronteiriço, identidade fronteiriça.

$* * *$

\section{Introducción}

Este trabajo surge como resultado alternativo del trabajo de investigación del autor en la localidad fronteriza sobre temáticas sociales y urbanas, desarrollado en diversas etapas entre 2006 y 2014. Dichotrabajo,cuyo mayor resultado se encuentra en Cantero (2010), contiene evidencias y senderos para considerar que la ciudad fronteriza de Nogales, en el estado de Sonora,al norte de México, ha enfrentado dinámicas sociales y políticas contribuyentes con su transformación urbana y cultural en los últimos años ${ }^{\mathbf{1}}$. Se podría decir que el cambio está en sugente,aunque la coordinación entre la sociedad local quizá es aún estrecha para lograr transformaciones urbanas sostenidas o de gran calado.Existen las bases necesarias y los actores suficientes para potenciar las fortalezas ciudadanas frente a los problemas cotidianos de la ciudad. La convergencia entre la organización social y gubernamental para reconvertir el espacio público de la ciudad es una de ellas. De aquí quelos actores participantes en colectivos culturales y artísticos han tenido un papel destacado en el activismo artístico-cultural orientado al espacio público urbano.

El documento se centra en exponer las trayectorias de algunos casos emblemáticos individuales y colectivos de artistas y colectivos culturales, con el objeto de comprender su papel en la localidad. Se organiza de la siguiente manera: la primera parte describe de forma somera el surgimiento de un actor cultural clave para comprender la trayectoria del arte público y sus promotores en la ciudad con el propósito de explicar en la segunda parte, su evolución hacia propósitos de acción colectiva mediante la conformación de un colectivo cultural como organización de la sociedad civil. 
Tal organizaciónadquirióla personalidad jurídica que le ha permitido establecer convenios de colaboración con el gobierno municipal (Leyva2013). En la tercera parte del texto se aborda el papel del arte y la cultura local como expresiones capaces de despertar el interés de nuevos espectadores en los espacios públicos mediante la acción colectiva orientada a la intervención artística-cultural de los espacios públicos para la intensificación de su uso y mejoramiento estético.

\section{La trayectoria social: unbreverecorrido contemporáneo del arte y cultura nogalense}

Es difícil concebir la trayectoria social, cultural y patrimonial del arte nogalense sin hablar del Taller Yonke. Dos personajes locales, Alberto Morackis y Guadalupe Serrano, crearon el "Taller Yonke de arte público" formalmente en 1996. Desde su origen como colectivo artístico el Taller alentóla colaboración dediversoshabitantes de Nogales interesados en fomentar el arte público, en levantar la voz por este medio,en resignificar el concepto de su frontera y apropiarse-reapropiarse del mismo. Como señala un tríptico que promovió una de sus obras más reconocidas,Border Dynamics, Taller Yonke ha desarrollado un concepto de arte público dirigido al rescate de los espacios de uso cotidiano (Varela 2012) y losespacios públicos deteriorados o abandonados (Serrano 2009), entre ellos la división fronteriza internacional materializada por un muro metálico. Con BorderDynamics el Taller alcanzó reconocimiento internacional y fue la ocasión para comenzar a recibir ciertos apoyos municipales para promocionar su trabajo. La frontera es tragedia para unos pero oportunidad para otros. El Taller supo aprovechar ese laboratorio de observación social, basado en el espacio público y suscircunstancias,paraobtener la proyección binacional e internacional que visibilizó su trabajo y multiplicó la atención sobre la problemática fronteriza. En este sentido, “el artista no desdibuja su experiencia; por el contrario se expresa desde ella” (Valenzuela 2000:23).

Hay por lo menos seis razones que destacan la presencia de Taller Yonke en la ciudad: 1) su trabajo está empapado de la realidad fronteriza con una profunda crítica al desarrollo industrial y urbanístico funcional, pensado desde el centro del país (Morackis y Serrano 2007); 2) la trayectoria social se acompaña de las difíciles condiciones de la ciudad por su topografía y ocupación económica local (industria maquiladora predominante); 3) el arte expuesto al público logra modificar el colorido del paisaje urbano. Hay un propósito público de invitar a la reapreciación de la ciudad e identificación de sus lugares y combatir la contaminación visual propagandística (Serrano, 2009); 4) hay un reconocimiento tácito y cotidiano de la ciudadanía por la obra del Taller, que a decir de Baldemar Gómez (Varela 2012), colaborador del Taller y músico local, se observa en la tendencia a la preservación de las obras y su valoración por la comunidad; 5) la condición de ciudad aún pequeña (no más de 230,000 habitantes según el censo nacional de población y vivienda 2010), permite cohesión y relación cotidiana frater- 
nal e intensa entre los miembros del Taller,colaboradores y ciudadanía, idea pocas veces abordada en trabajos académicos debido a su dificultad de medirla o presentarla como variable científica según el paradigma positivista. Una situación que expresa además el potencial de conformación de otros colectivos y; 6) el Taller logró proyección internacional gracias al apoyo gestionado por organizaciones como Beyond Borders Binational Art Foundationo de académicos de la Universidad de Arizona (Serrano2009; Varela 2012). ${ }^{2}$

La trayectoria social incluye la condición del desarrollo de la cultura y el arte en la localidad de forma libre,desde abajo, ${ }^{3}$ con la sociedad, a pesar de llegar a obtenerse recursos públicosen pago o beca para su desarrollo. Significa que se abrió una brecha de perspectivas porque "mientras el pensamiento político está preocupado por la gobernanza, o la economía por la gestión de los recursos o las finanzas, los artistas suelen estar ocupados experimentando con otras posibilidades de vivir y representar lo que se vive” (García 2013). No se puede pensar o repensar lo que se vive si no se vive desde la perspectiva de la sociedad. En el caso de Nogales el Taller Yonke ha expresado con claridad su mirada desde la perspectiva social sobre las condiciones de vida de la ciudad y sus cerros, del obrero de la industria maquiladora, de la frontera, sus conflictos y oportunidades, del nativo sonorense, de la gente.Deesecollageprovieneel propio nombre del Taller (Yonke,regionalismo referido a una desarmadorade autopartes) y el reconocimiento social a su trabajo expresado incluso en su obra (ver fotografía1).La observación de este caso particular habla de su esfuerzo como organización cultural que,sinembargo,requería nuevos horizontes y alianzas para incorporar a las nuevas generaciones de artistas y “cultureros"-gestores culturales, como se autonombran en la localidad? al desarrollo local del arte y cultura como critica o respuestasimbólica, también de intervención de los espacios públicos, a los problemas sociales que acontecieron en la ciudad.

\section{Fotografía 1. Pintura Sueño americano (Fragmento). Técnica mixta, Taller Yonke.}

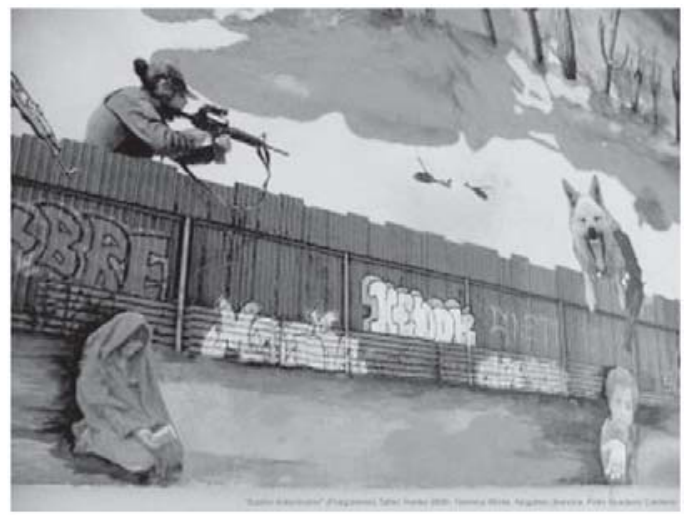

Fuente: Fotografíade autoría propia, 2010

.La pintura se exhibió en el Centro Cultural Los Nogales. 
La necesidad de crear y animar nuevos espacios públicos en la ciudad, la cual históricamente careció de ellos (Cantero 2010), llevó en 1999 a un grupo de al menos veintiún "cultureros” y artistas a solicitar al gobierno municipal, la creación de un proyecto cultural que abarcara mucho más de que los limitados cauces oficiales o las expresiones culturalescomerciales, atomizadas y presentadasenlacasa de cultura y el entonces único auditorio de la ciudad. El propósito concreto fue tratar de despertar el interés del gobierno municipal en la promoción del arte y la cultura para mostrar que se contaba con el capital artístico suficiente y con un grupo de artistas, aunque aparentemente dispersos y con intereses diversos, capaces de organizarse para lograr un nuevo organismo municipal encargado del tema. ${ }^{4} \mathrm{El}$ caso muestra el interés de un sector de la sociedad local por privilegiar la cultura en una ciudad que llegó a considerarse frontera blanca o la Atenas de Sonora en los años cincuenta (Cantero 2010:65; Morackis y Serrano 2007:3), cuyo carácter parece haberse perdido con la explosión demográfica simultánea al crecimiento de la industria maquiladora entre los años ochenta del siglo xx y los primeros años del nuevo siglo (ver gráfica 1), produciendo además de déficits de servicios y espacios públicos (Cantero 2010:152), carencias culturales y pasividad social. Dicha experiencia puede considerarse como pionera en el establecimiento de nuevas relaciones sociedadgobierno para favorecer la cultura al descartar la persecución de ideas o sospechas de activismo político de parte de las autoridades y el partido gobernante, tal como ocurrió a finales de los años setenta (Monroy 2009).

\section{Gráfica 1. Población de Nogales.}

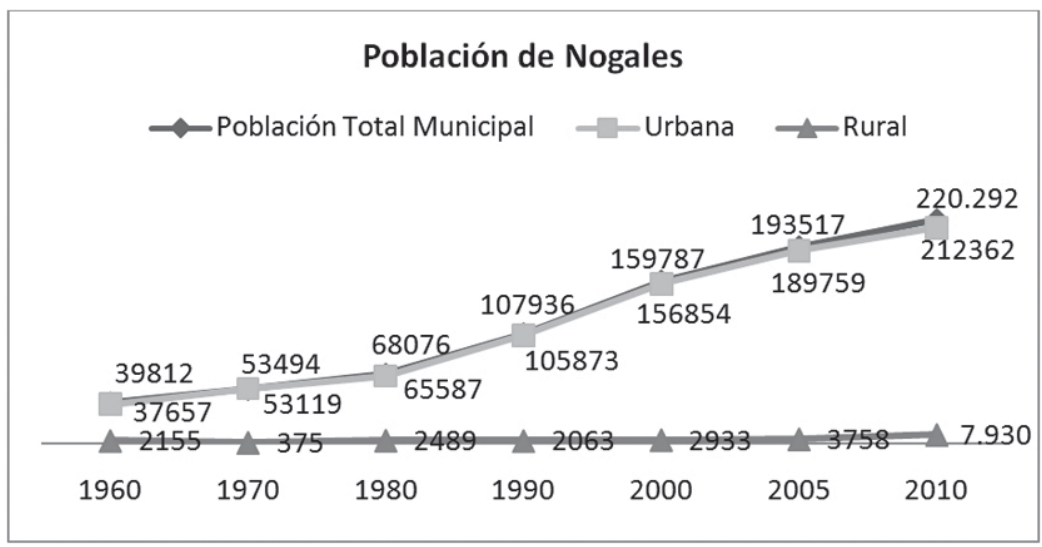

Fuente: Con datos de INEGI,

Censos generales de población y vivienda y Conteo de población 2005. 


\section{Los artistas y colectivos en su papel como sociedad civil organizada (organizándose)}

En la trayectoria social del arte y la cultura nogalense como una forma de respuesta a los problemas sociales locales, Nogales tiene una ventaja significativa que reposa en la solidaridad y el sentido de comunidad de sus habitantes, atribuibles a la historia, tamaño y condiciones específicas de la ciudad.Por pequeñas o grandes que puedan ser las acciones colectivas, movilizaciones o manifestaciones de protesta o colaboración, éstas han tenido visibilidad en el espacio público central. Como en otras ciudades fronterizas del norte de México, se sabe que Nogales se expandió desde la división internacional hacia el sur, convirtiéndose la proximidad a la división en su lugar central, no el sentido que lo entienden los economistas de las teorías de la localización como concentración económica y de actividades productivas, sino como lugar central de los usos sociales del espacio público, de las calles, de las vialidades, de las plazas públicas, del ofrecimiento urbano a transitar por estas zonas y contradictoriamente apermanecer para apreciar la diferencia y variedaddeobjetos, personas, circunstancias, incluso culturas y lenguas concurrentes.

Los habitantes de esta frontera y en particular los artistas y colectivos están plenamente conscientes de dicha condición. La valoran y han dirigido sus expresiones y trabajos hacia tales espacios.Las intervenciones artísticas vistas como movimientosde protesta en la ciudad para la utilización del espacio público central se han desarrolladode forma dispersa en el tiempo. Pero losignificativoy recurrente ha sido tomar la división internacional y manifestarse en secciones del muro fronterizo con métodos noviolentos, que basados en Sharp (1988), han ido desde los actos públicos simbólicos que requieren organización simple, hasta formas y producciones artísticascon mayor complejidad, con la finalidad de llamar la atención medios de comunicación locales, estadounidenses e internacionales. Es cuando las intervenciones culturales y artísticas interpretan como ventajosa la condición fronteriza, aspecto además relacionado con el principio gandhiano de Swadeshi, que "se refiere a la valoración de lo cotidiano, de lo local y de lo autóctono" (Ballesteros-Peluffo 2012: 48) para producir expresiones simbólicas propias (ante la convivencia permanente con lo externo), incluso como discursos visuales defensivos y accesibles para el resto de la comunidad,dadassus localizaciones centrales o en puntos concurridos del espacio público urbano. Se tiene registro de que las actividades de protesta se presentaron desde principios de los años noventa del siglo xx en la localidad, acompañadas de expresiones inicialmente influidas por la corriente punk de grupos musicales locales como La Merma, Democracia Real o Estupidez Crónica (Varela 2010). El propósito general ha sido la apropiación simbólica bajo un discurso crítico,del espacio próximo a la división internacional y en el muro fronterizo: protestar en la línea y el muro fronterizos, "retirarles su estatus de inmaculados" (Leyva, en Varela 2010), pensamiento compartido e internalizado entre artistas, colectivos y sociedad local y también relacionado con sus trabajos y movilizaciones allí localizados (fotografías 2 a 5). 
Fotografía 2. Paseo de la humanidad.

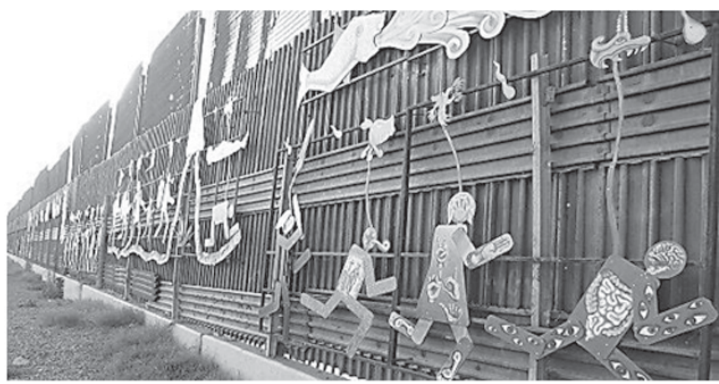

Fuente: Autoría propia, 2009.

Fotografía 3. México opuesto(original).

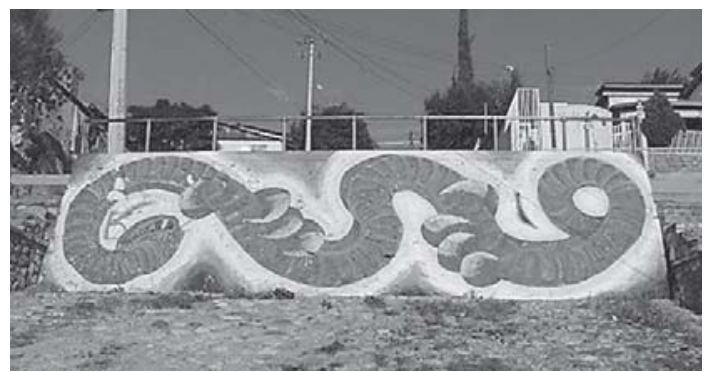

Fuente: Autoría propia, 2009.

El mural México Opuesto fue confundido como grafiti en diciembre de 2012 y borrado por personal de imagen urbana. Taller Yonkey activistas protestaron y lo repintaron días después. Se ubica en la calle Pierson e Ingenieros a unos trescientos metros de la división internacional.

Fotografía 4. Intervención en el muro fronterizo.

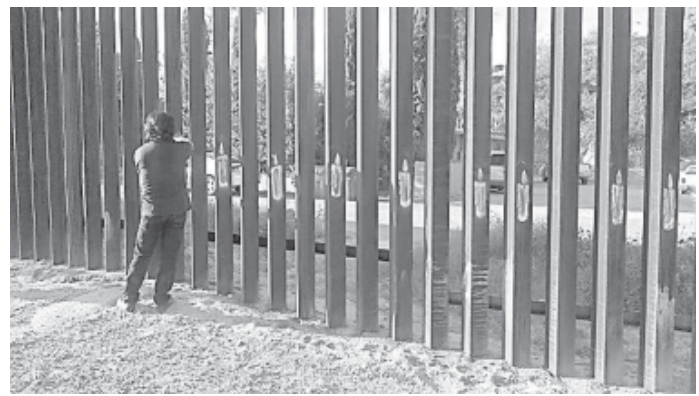

Fuente: Guadalupe Serrano, perfil de Facebook, octubre de 2013. 
Fotografía 5. Border Dynamics, 2003.

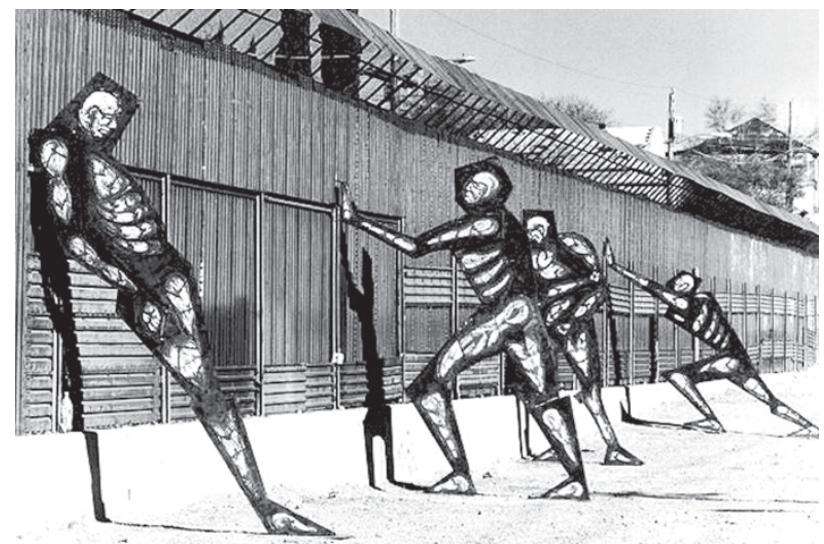

Fuente: Taller Yonke, en: https://www.facebook.com/photo.php?fbid= $1239038809275 \&$ set $=$ a. $1239038209260.2031082 .1028424966 \&$ type $=3 \&$ theater recuperado 29 de marzo de 2016.

La evolución de singulares movilizaciones y expresiones existentes en una ciudad pequeña, tradicionalista aún en muchos aspectos de la vida cotidiana, ha traído como resultado: 1) la resignificaciónde la identidad del nogalense, de sus habitantes; 2) la mutación continua de la estética urbana; 3) la creación de referentes comunitarios; 4) la apropiación del rol de denuncia pública y; 5) multiplicación de ciudadanos interesados y creación de nuevos colectivos culturales.

La idiosincrasia de la población local puede considerarse como un factor que ha permitido explorar nuevos caminos mediante la suma de voluntades individuales y la captación de nuevos talentos. Es decir, que existe la posibilidad de acompañamiento en la diferencia y la diversidad artística. De tal reflexión surge en el año 2011 a propuesta de Guadalupe Serrano y con el interés de artistas y "cultureros"de crear un colectivo que reúne dicha diversidad cuyo propósito es "hacer algo por la ciudad" lo que implica intervenir el espacio público y conlleva gradualmente a mostrarse como sociedad civil formalmente organizada. A la propuesta se le llamó Taco de Perro ${ }^{5}$,colectivo que cuenta con estatus de sociedad civil,con carácter autogestivo para proyectar actividades artístico-culturales. Uno de los propósitos originarios de la creación del colectivo ha sido captar a jóvenes sin espacios de expresión, principalmente grafiteros, para enfocar su trabajo hacia el desarrollo de perfiles y técnicas artísticas y consecuentemente evitar su criminalización (Leyva 2013; Ídem 2014)

Algunos miembros del colectivo han desarrollado un proceso de aprendizaje apoyado en las relaciones profesionales de sus liderazgos que 
lo convirtieron en respaldo del gobierno municipal, ciudadanía y otros organismos civiles locales y estadounidenses (Leyva 2013; Ídem 2014). Sin embargo, ha sido un proceso nuevo para la mayoría de sus integrantes, más bien ejercitado por los integrantes más experimentados, quienes han obtenido apoyos para continuar con montajes de obra plástica en la barda fronteriza. Aunque el colectivo no ha activado de manera conjunta dicha habilidad, la capacidad para iniciarla es potencial y podría realizarse en un momento de decisión interna, justo cuando se presente la oportunidad de obtener recursos para iniciar proyectos.

\section{Figura 1. Logotipo del colectivo Taco de Perro.}

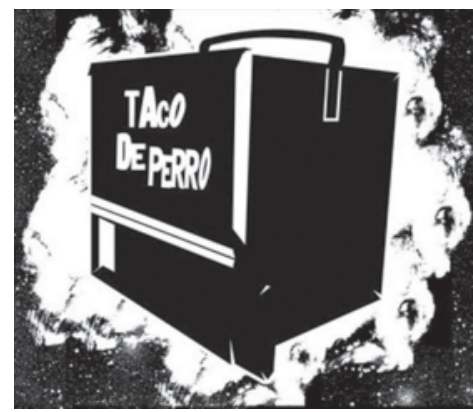

Fuente: Perfil de Facebook del colectivo, publicado (y consultado) en octubre de 2013.

La experiencia de constitución del colectivo Taco de Perrocomo sociedad civil organizada en Nogales no corresponde a la idea planteada de los organismos de la sociedad civil (en adelante osc) como Tercer Sector (asistenciales), relacionada con el desarrollo conceptual de la sociedad civil en Estados Unidos o países con economía de mercado avanzada. Tampoco muestra rasgos de oscsdemocratizantes de la vida pública en el plano político. La reflexión del colectivo no ha explorado la posibilidad de actuar por esa vía de manera directa. Sin embargo, su interés por incidir en la práctica en el espacio público urbano mediante la propagación de las expresiones artísticas y culturales de sus integrantes en la localidadhabla de un osc que, aunque ha tenido sus bemoles en tal cometido (Leyva 2013), supo aprovechar la fase de convivencia democrática local producida a raíz del ciclo de alternancia municipal de 2006 a 2012. Es una condición con la que grupos anteriores no convivieron ?el documental de Varela (2010) lo expresa también en el sentido de la organización casi exclusiva para la protesta influida por el ambiente punk de los noventa?, pero que los contemporáneos parecen haber capitalizado.

Taco de Perro tiene una condición colaborativa reciente como osc,al haberse alternado la fase autoritaria de la política local. Pero las oportunida- 
des de acción para los miembros del colectivo (al menos una decena de personas, las más constantes) se han multiplicado al firmar convenios de colaboración con la dependencia municipal de cultura en Nogales y relacionarse con organismos educativos, osclocalesy externas de temáticas similares y diversas. Un ejemplo es su incursión en espacios de educación media superior, donde se han pintado murales y grafiti juvenil con respuesta favorable de diversos participantes:

Hemos trabajado con algunos grafiteros, por ejemplo, con los cuales hemos hecho ya unos murales, creo que unos tres, estamos en vísperas de hacer otro mural también. Pero no solamente un mural de una barda apartada en una colonia, sino un mural que represente algo de lo que es el espacio social en la frontera. Algo que no solamente la gente lo vea sino que los vean los chavos del barrio o las doñitas del barrio, sino que lo vea la gente que transita cotidianamente por las calles más concurridas de la ciudad, los extranjeros que vengan (Leyva 2014).

El sentido del trabajo de intervención artística y cultural del colectivo se relaciona estrechamente con los objetivos de la acción noviolenta porque esta "es la escogencia de una fuerza creadora, capaz de transformar positivamente y guardar coherencia entre principios y fines.” (BallesterosPeluffo 2012: 55) y porque hay conciencia y un claro activismo comparativo en el mismo sentido:

Me he dado cuenta que en [ciudad] Juárez, algunos creadores están muy cargados a la situación de la violencia, porque Juárez es una de las ciudades que más ha sufrido [...] la violencia y muchos creadores han hecho una apología de la violencia y han resaltado su trabajo creativo a través de la violencia y no estoy de acuerdo con ellos [...] Entonces la idea es, de que aquí en Nogales cualquier gente que se integre al proceso de creatividad lo haga para todos. No solamente para alguien de las colonias, para un determinado sector o para un grupo o para un cierto gusto, sino que toda la gente se conjugue y empiece a ver y analizar y diga " $j a h$ ! esto es parte de Nogales, este mural, esta figura metálica, este grafiti que está aquí” forma parte de un todo, de una identidad fronteriza. Es una de las ideas primigenias de nosotros, mantener esa identidad cultural (Leyva 2014).

El trabajo de Taco de Perro se conoce por su organización colectiva pero también por el trabajo individual y la trayectoria de varios de sus integrantes, entre ellos los actuales miembros del Taller Yonke, Guadalupe Serrano y Diego Taddei, el periodista local, Raúl Leyva, el músico Baldemar Gómez (por mencionar algunos) y un grupo de nuevos talentos con formación académica artística. La suma de talentos abona a la trayectoria del colectivo y avala su trabajo en el espacio público o su intervención en la cercanía de los barrios obreros, la penitenciaria y en la proximidad de la división fronteriza.Los miembros del colectivo han podido ingresar a los barrios conflictivos y acercar nuevas opciones culturales a sus habitantes 
en colaboración con el Circo Volador, una osc de la ciudad de México reconocida internacionalmente por su trabajo a favor de la juventud en escenarios de violencia. Este trabajo no produjo soluciones inmediatas a problemas juveniles?difíciles de paliar?,sinorutasinicialesde aprendizaje en la práctica para la intervención comunitaria, con una metodología de acercamiento comprensiva y participativa, que tuvo como propósito reunir a los jóvenes de tres colonias de Nogales para el uso sus espacios públicos y centros comunitariosmedianteel ofrecimiento de expresiones culturales y artísticas que fueran de su interés. ${ }^{6}$

\section{¿Por qué el arte y la cultura? ¿qué se resuelve, qué se gana o qué se obtiene?}

$\mathrm{Al}$ revisar la historia de la localidad,seaprecia que Nogales es una ciudad que experimenta (sin pensarse como frase cliché de las ciudades fronterizas) cambios sociales y urbanos vertiginosos y recurrentes (Flores 1987; Mascareñas 2000; Suárez 2007). Uno de sus cambios urbanos recientes fue la creación masiva de espacios culturales y recreativos entre 2006 y 2012 que atrajo a nuevo público usuario al espacio público de la ciudad (Cantero 2010),situación que cuestionó seriamente el calificativo metafórico y estéreotípicode las ciudades fronterizas del norte de Méxicocomo desiertos culturales (Valenzuela 2000; Ídem 2003).Hubo nuevos espacios de uso colectivo creados para fomentar expresiones artísticas y culturales además de lúdicas y recreativas. Pero en algunos espaciospúblicos de uso colectivo,especialmente los ubicados en tres barriosconflictivos, se favorecióla presencia y el trabajo de intervención artístico, cultural y con propósitos noviolentosde miembros del colectivo Taco de Perro.Las actividades se llevaron a cabo en colaboración con Circo Volador con fondos públicos de la Secretaría de Desarrollo Social Federal (Sedesol) en su programa Hábitat y con fondos federales del Subsidio para la Seguridad en los Municipios (Subsemun). Lo innovador del trabajo entre Taco de Perro y Circo Volador fue la implementación de acciones de búsqueda de jóvenes en tres colonias de la ciudad con los índices más altos de violencia y marginación. Se realizaron acercamientos con adolescentes y preadolescentes bajo el enfoque de prevención de violencia con estrategias similares a las reconocidas por el Banco Mundial, en particular en las estrategias de capacitación, deporte y cultura con muy buena aceptación de parte de los habitantes de las colonias. Se proyectó llevar a cabo las estrategias de intervención en los espacios de uso público frecuentados por jóvenes como canchas de básquetbol (que son la principal infraestructura comunitaria de esparcimiento en las colonias de la ciudad) y en los centros comunitarios creados desde 2012. La desventaja del trabajo conjunto fue que sólo un par de miembros del colectivo participaron activamente en la implementación de estrategias de prevención. Al finalizar los proyectos y el programa,el colectivo no sistematizó ni interiorizó el aprendizaje obtenido, esto aunado a que el organismo civilexterno a la ciudad (Circo Volador) se retiró cuando los fondos de Sedesol y Subsemun dejaron de suministrarse debido a la conclusión de los periodos de operación de los 
programas y convenios implementados. Es decir, fue un programa público finito con participación de la sociedad civil local y externa. Pero cabe subrayar la identificación y el aprovechamiento de los lugares de reunión juveniles como espacios de expresión, así como en el aprovechamiento de las plazas públicas centrales y de diversos espacios en la proximidad de la barda fronteriza que han formado parte de los lugares objetivo del colectivo para atraer público general y joven fuera del auspicio de programas y fondos públicos.

Las acciones antedichas han abonado a laresignificación del uso del espacio público y de las expresiones culturales y artísticas en la localidad. Se generó una nueva interpretación sobre el concepto de espacio público entre los integrantes del colectivo y “cultureros” al abandonarla interpretación urbana funcional de los espacios de uso colectivo (lugares de tránsito, de descanso o comercio), y adoptar su interpretación como idóneos para las expresiones culturales (lugares socialmente recuperables,reutilizables; lugares artísticamenteintervenibles, pintables, coloreables). Pero en dicha resignificaciónhaydimensiones prácticas entre la comunidad artística-cultural de Nogales, porque la modificación del uso de espacios de uso colectivocondujopor ejemplo, al retiro de la estigmatización de artistas y “cultureros” (por presencia ajena y apariencia personal) cuando establecieron interacciones estrechas con habitantes de los barrios conflictivos y con medios de comunicación locales, aspecto que ha fincado el gradual reconocimiento social de los grupos de activistas culturales. Con esto se observa que "el arte público participa en la resignificación de espacios y fronteras, incorpora elementos que redefinen sus aspectos significantes y cognitivos, pero también participa en la disputa simbólica” (Valenzuela 2000: 19).

En palabras de uno de sus actores, se observa la superación de los objetivos de la integración en un colectivo para trabajar por el arte y la cultura:

“La gente hace conciencia de la problemática fronteriza mediante el trabajo del colectivo, pero es aún difícil observarlo en poco tiempo. Los resultados del colectivo no han sido todos exitosos, han existido bemoles. Sin embargo esta condición se observa como un proceso de aprendizaje, con entusiasmo para continuar trabajando. El saldo ha sido mucho más favorable de lo que habíamos pensado, porque originalmente se consideró crear una galería. Sin embargo, las actividades del colectivo se han diversificado hacia el espacio público” (Leyva 2013).

En tal cambio de percepción social, que involucra una evolución del trabajo artístico e intervención cultural, deja de usarse el significado de "la frontera como cerca y desierto” (Malagamba 2003:372) , el cual -incluso- se ha reflejado en la obra de los artistas nogalenses, porque la reflexión colectiva producto de la acumulación de su trabajo ha llevado a cuestionar a la frontera desde la perspectiva crítica identitaria, la del“cómo somos aquí, 
por qué somos así y cómo es que venimos de todos lados.” La versión nogalense del arte fronterizo se acerca a una versión con amplio sentido de crítica social expresadatantoen la plástica, como en la lírica o en la música y por tanto, la propagación del arte y la cultura entre los artistas nogalenses presenta una tendencia de amplia aceptación social e interacción cotidiana con su público y sus nuevos públicos. Lo anterior demuestra en parte, que la trayectoria del arte y cultura nogalenseen sus diversas expresiones o modalidades, ha sido una trayectoria que ha partido desde la base social. Indica que sus actores no son del tipo de artistas encumbrados que miran hacia abajo a su público.Forman parte de la comunidad y conocen de inmediato las problemáticas sociales porque las viven de forma cotidiana. Sólo resta añadir que la capacidad gubernamental en la promoción del arte y la cultura ha sido una capacidad mermada y proyectada en acciones de corto alcance por limitaciones presupuestales (Cantero, 2010), que durante algún tiempo se relacionaron con expresiones culturales comerciales y únicamente para algunos barrios seleccionados, situación distinta (y criticada) a las propuestas de los mismos los colectivos por sus estrategias emprendidas.

\section{A modo de conclusión}

A lo largo del texto se dieron detalles y argumentos sobre el hecho de que la trayectoria social de artistas y colectivos culturales de Nogales seencuentraestrechamenterelacionada con su espacio público.Hay una preocupación colectiva por tomar las riendas de la ciudad, una ciudad difícil por su topografía con percepción de abandono urbano, que suspendió el pasado autoritario delosgobiernos priistas hegemónicos hasta 2006 (con alternancias en 2012 y 2015). En esta frontera se encuentran los conocidos problemas de tráfico de drogas, tráfico demigrantes,violenciay delincuencia cotidiana aunados al malestar generado por la tragedia humanitaria,como resultado de la guerra contra el narcotráfico, emprendida por el gobierno federal 2006-2012 en múltiples dimensiones.Alo anterior hay que sumar los problemas de carencias en servicios públicos, incertidumbre en la tenencia de la tierra, vivienda precaria y violencia de género, entre otros.

El arte y la cultura de Nogales y sus actores han emprendido diversas acciones como una forma de responder a la necesidad de apropiación del espacio público, de criticar la adversidad social prevaleciente y la problemática fronteriza. Se pueden listar decenas de accionesentre 2012 y 2015 , por ejemplo, del colectivo Taco de Perro, ${ }^{7}$ quienes han valorado que la respuesta de la población ha sido desde baja, hasta muy buena.Sin embargo, los actores culturales no son actores destinados ni ocupados en resolver las problemáticas públicas aludidas (Diego Taddeien Varela, 2012), porque para ello se requiere mucho más que la implementación de acciones artísticas. Se requiere un compromiso significativo entre sociedad local y las tres escalas de gobierno, al menos para matizar los problemas públicos. Los actores del arte y la cultura local responden a las problemáticas de la ciudad de acuerdo con su rol, de una manera suave, con un trabajo gradual que invita al espectador a concientizarse de su entorno, de sí mismo y cuyo 
contenido muestra criticas importantes a problemas de la localidad como los derivados del desarrollo industrial, la crisis migratoria, la militarización fronteriza, el tráfico de drogas y su violencia inherente. El trabajo logrado por la comunidad artística y cultural en Nogales rompe con los esquemas dela cultura y elartepomposos,elitistas, porque está influido por su realidad y por la práctica del arte crítico encabezada por Alberto Morackis a principios de los años noventa del siglo xx. Tales expresiones debaten la identidad del nogalense:su pluriculturalidad; la fusión de opiniones; la mezcla de muchas identidades, muchas formas de pensar. Se abona al reconocimiento de lo diverso, de la diversidad de los lugares de procedencia de los habitantes de la ciudad (Leyva 2013) y de los mismos actores aquí señalados. Ello da pie para preparar el cierre con la siguiente cita: "la comprensión no excusa ni acusa: ella nos pide evitar la condena perentoria, irremediable, como si uno mismo no hubiera conocido nunca la flaqueza ni hubiera cometido errores. Si sabemos comprender antes de condenar estaremos en la vía de la humanización de las relaciones humanas.” (Morin, 1999:55, énfasis original).

Por último es importante subrayar el reconocimiento del patrimonio artístico de la ciudad creado y promovido por los grupos locales y los medios de comunicación, el cual aporta sentido de identidad al nogalense. La percepción de isla cultural parece haberse modificado gracias al reconocimiento internacional alcanzado por la acumulación de obras de arte público a lo largo del tiempo, ${ }^{8}$ por la colectivización del activismo artístico y cultural, lo mismo que por la presencia de expresiones musicales de grupos locales.De acuerdo con las tendencias observadas, se esperaría que la aparición y convivencia de nuevos artistas visuales y escritores con los ya arraigados genere nuevas dinámicas de aprendizaje. En caso contrario lo interesante sería conocer los factores o variables que limiten la organización o aparición de nuevos grupos y colectivos.Pero de cualquier forma las tendencias serándignas de análisis posteriores en función de las condiciones sociales de la ciudad. 


\section{Notas}

${ }^{1}$ Presentado en el 3. ${ }^{\text {er }}$ Congreso Internacional Problemas y Respuestas de las Ciudades Fronterizas, realizado en Ciudad Juárez, Chihuahua,7 y 8 de noviembre de 2013.

${ }^{2}$ Valdría la ocasión revisar el documental de Varela (2012) para conocer además de la trayectoria social, brevemente, la trayectoria personal y política de los miembros y personas cercanas al Taller Yonke.

${ }^{3}$ Término usado para identificar derechos sociales y proyecciones de la acción colectiva con iniciativa genuinamente social. Tiene un componente jurídico ligado a ciertos derechos como el derecho de petición, movilización, la solicitud de información o la rendición de cuentas. Dada la historia de los regímenes autoritarios en diversos países, los derechos enunciados se han considerado como concesiones estatales paternalistas (Pisarello 2008: 158,176). El concepto, asimismo enfoque, concibe a los actores sociales como sujetos capaces de autotutelar sus derechos, a partir de un ejercicio permanente de responsabilidad política, con la finalidad de que tales derechos lleguen a permanecer en el marco jurídico como preferenciales. Al mismo tiempo es la castellanización en la literatura de políticas públicas, del anglicismo bottom-top, pero para el análisis de la acción pública según Cabrero (2005) implicaría tener un enfoque de la acción, desde la perspectiva de los actores o sociales sin poder público. En este trabajo se expresa como la acción emprendida en el espacio público proveniente de los colectivos artístico-culturales independientes.

${ }^{4}$ Los escritos de petición se encuentran en el archivo histórico municipal de Nogales: expediente 31, 1999, Caja 134, paquete 4, de los cuales se tiene copia simple.

${ }^{5}$ El colectivo lleva el nombre de Taco de Perro, un tipo de alimento típico de la localidad que consiste en tacos dorados (tipo dobladita: tortillas de maíz dobladas y fritas en aceite) rellenos de papa con carne (los lugareños bromean con que la carne es de perro), servidos con repollo rayado y salsa de jitomate picado con chile (ají mexicano) seco machacado. La característica especial de estos tacos es que son mantenidos en un tipo de canasta-horno metálica, calentada con piezas de carbón ardiente en la base para ser vendidos en la calle a un precio aproximado de medio dólar por pieza. La popularidad de este alimento en la localidad, hizo pensar a los miembros del colectivo en tomar dicho nombre (Leyva, entrevista, 2013), por reconocerse en la diversidad, bajo un lugar y condición común: la frontera nogalense y sus costumbres.

${ }^{6}$ El proyecto fue conocido como "Consultoría para la asistencia técnica e intervención con jóvenes en situación de riesgo de violencia social” desarrollado por el Centro de Arte y Cultura Circo Volador A. C., y el investigador Héctor Castillo Berthier del Instituto de Investigaciones Sociales de la UNAM. Se aplicó en siete ciudades del país, incluida Nogales, como parte de la política de intervención urbana del programa Hábitat de la Secretaría de Desarrollo Social Federal en el último semestre de 2012, proyecto en el cual participó como investigador en acción participativa el autor de este texto.

${ }^{7}$ Cotejable en su perfil de Facebook: consultado de manera periódica. Última, 29 de marzo de 2016.

${ }^{8}$ Por ejemplo, Forward ThinkingMuseum. Stefan Falke. "La Frontera: 
Polis, Revista Latinoamericana, Volumen 15, $N^{\circ}$ 43, 2016

Artistsalongtheus/Mexicanborder” en http://www.forwardthinkingmuseum.com/ exhibitions/solo_falke_NO_01.php consultado 2 de octubre de 2013, vigente 29 enero 2016. 


\section{Bibliografía}

Ballesteros-Peluffo, Gilma (2012), Noviolencia y desobediencia civil, en Desafíos (24-2), Semestre II de 2012, Bogotá.

Cabrero, Enrique (2005), Acción pública y desarrollo local, FCE, Ciudad de México.

Cantero, Gustavo (2010), Evolución de los espacios culturales y recreativos en Nogales, Sonora (1997-2009). Planeación municipal, urbana y gestión pública como promotores de su cobertura, Tesis de Maestro en Desarrollo Regional, El Colegio de la Frontera Norte, Tijuana.

Flores García, Silvia (1987), Nogales: un siglo en la historia, Secretaría de Fomento Educativo y Cultura de Sonora, Hermosillo.

Leyva, R. (2013, octubre 11), “El Colectivo Taco de Perro”, entrevista (vía telefónica) por Gustavo Cantero.

Ídem, (2014, junio 18), "El colectivo Taco de Perro y sus acciones como OSC para el mejoramiento del entorno urbano en Nogales”, entrevista por Gustavo Cantero[trabajo de campo], Nogales.

Malagambia, Amelia (2003), “Una visión del arte fronterizo. El poder del lugar y las geografías recordadas” en Valenzuela, José Manuel (Coord.), Por las fronteras del norte: una aproximación cultural a la frontera MéxicoEstados Unidos, Colección Biblioteca Mexicana, FCE-Conaculta, Ciudad deMéxico.

Mascareñas, Enrique (2000), El Nogales de Ayer 1880. Historia de Nogales Sonora que incluye las memorias de Don Remigio Lizárraga Z., Escritas con aportes e investigaciones del QFB. Enrique Mascareñas S., sin editorial, Nogales.

Monroy, Óscar (2010, febrero 26), “Espacios y actores culturales en Nogales” entrevista por Gustavo Cantero [trabajo de campo], Nogales.

Morackis, Alberto y G.GuadalupeSerrano(2007), “Esta ciudad se pasó de la línea: contexto, formas y actores de la frontera de México y Estados Unidos de Norteamérica”, sin pie de imprenta, Nogales.

Morín, E. (1999), Los siete saberes necesarios para la educación del futuro,UNESCO, París.

Pisarello, Gerardo (2008), “Los derechos sociales y sus garantías: notas para una mirada desde abajo” en Courtis, Christian (Comp.), Desde otra mirada.Textos de Teoría Crítica del Derecho, Eudeba, Madrid.

Serrano, Guadalupe (2009, julio 29) El Taller Yonke y los espacios públicos 
en Nogales, entrevista por Gustavo Cantero [exploración de campo], Nogales.

Sharp, Gene (1988), La lucha política noviolenta. Criterios y métodos, Ediciones ChileAmérica CESOC, Santiago.

Suárez, Alberto (2007), Mi historia... Nuestra Historia 1884-1918-2007, H. Ayuntamiento de Nogales Sonora, Nogales.

Valenzuela, José (2000), “Formas de resistencia, corredores de poder: Arte público en la frontera México-Estados Unidos” en García Canclini, Néstor y José Manuel Valenzuela, Intromisiones compartidas: arte y sociedad en la frontera México/Estados Unidos, Conaculta, Tijuana.

Ídem (2003), “Centralidad de las fronteras. Procesos socioculturales en la frontera México-Estados Unidos” en Por las fronteras del norte: una aproximación cultural a la frontera México-Estados Unidos, Colección Biblioteca Mexicana, FCE-Conaculta, México.

\section{Consultas a medios digitales}

García Canclini, Néstor (2013), “La cultura global fue una ficción”, entrevista por Marina Oybin, recuperado de http://www.revistaenie.clarin.com/ ideas / filosofia/Nestor-Garcia-Canclini-cultura-globalficcion_0_997100309.html, vigente 29 de marzo de 2016.

Varela, Agustín (Tino) (2010), La Merma, 15 años de camino, Nogales, México, Ve! Films, en https://www.youtube.com/watch?v=cMN6cfrpkV4 vigente 29 de marzo de 2016.

Ídem (2012), Arte público Yonke ciudad a cuerpo, Nogales, México, Ve! Films, en https://www.youtube.com/watch?v=Iy9D2IDAJUM, vigente 29 de marzo de 2016.

Recibido: 30.01.2016

Aceptado: 05.04.2016 